\title{
Ambulatory Care Provided by Office-Based Specialists in the United States
}

\author{
Jose M. Valderas, $M D, P b D, M P H^{1}$ \\ Barbara Starfield, $M D, M P H^{2}$ \\ Christopher B. Forrest, MD, $P b D^{3}$ \\ Bonnie Sibbald, MSc, $P b D^{1}$ \\ Martin Roland, CBE, DM, FRCGP, \\ FRCP, FmedSci ${ }^{1}$ \\ 'National Primary Care Research and \\ Development Centre, The University of \\ Manchester, United Kingdom \\ ${ }^{2}$ Department of Health Policy and Manage- \\ ment, Johns Hopkins Bloomberg School of \\ Public Health, Baltimore, Maryland \\ ${ }^{3}$ Department of Pediatrics, Children's Hos- \\ pital of Philadelphia, University of Penn- \\ sylvania School of Medicine, Philadelphia, \\ Pennsylvania
}

Conflicts of interest: none reported

\section{CORRESPONDING AUTHOR}

Jose M. Valderas, MD, PhD, MPH

National Primary Care Research and Development Centre

The University of Manchester

Williamson Bldg

Oxford Rd

Manchester M13 9PL, UK

jose.valderas@manchester.ac.uk

\begin{abstract}
PURPOSE Increasing use of specialist services in the United States is leading to a perception of a specialist shortage. Little is known, however, about the nature of care provided by this secondary level of services. The aim of this study was to examine the content of care provided by specialists in community settings, including visits for which the patient had been referred by another physician.
\end{abstract}

METHODS Nationally representative visit data were obtained from the National Ambulatory Medical Care Survey (NAMCS) for the years 2002 through 2004. To describe the nature of care, we developed a taxonomy of office-based visit types and constructed logistic regression models allowing for adjusted comparisons of specialty types.

RESULTS Overall, $46.3 \%$ of visits were for routine follow-up and preventive care of patients already known to the specialist. Referrals accounted for only $30.4 \%$ of all visits. Specialists were more likely to report sharing care with other physicians for referred, compared with not referred, patients (odds ratio [OR] $=2.99 ; 95 \%$ confidence interval [Cl], 2.52-3.55). Overall, $73.6 \%$ of all visits resulted in a return appointment with the same physician, in more than one-half of all cases as a result of a routine or preventive care visit.

CONCLUSIONS Ambulatory office-based activity of specialists includes a large share of routine and preventive care for patients already known, not referred, to the physician. It is likely that many of these services could be managed in primary care settings, lessening demand for specialists and improving coordination of care.

Ann Fam Med 2009;7:104-111. DOI: 10.1370/afm.949.

\section{INTRODUCTION}

$\mathrm{T}$ There is uncertainty as to whether the United States should be training more specialists. Some argue that demand for specialists is rising and shortages are already apparent, ${ }^{1-5}$ while others disagree. ${ }^{6,7}$ Better information about the content of and need for care that specialists are providing in the United States would help to inform this debate. ${ }^{8}$

The functions of primary care are well established and widely accepted ${ }^{9}$ : first-contact care, continuity with the same provider over time, delivery of a comprehensive range of services, and coordination of care. ${ }^{10}$ These benefits, best achieved when provided by a single, regular source of care, ${ }^{11}$ form the basis of the recent medical home model..$^{12,13}$

Specialist physicians are needed to address conditions too uncommon for primary care physicians to maintain competence ${ }^{14}$ and for procedures that require a high level of technical expertise or specialized equipment. ${ }^{15,16}$ Theoretically, these activities should be the core functions of specialized care, but whether such is the case in practice or how it is accomplished is unknown.

As most specialty care in the United States is clinician-initiated ${ }_{1}^{17}$ decisions that specialists make about routine or follow-up care can have important implications for the volume of their work and physician workforce projections. Referrals ${ }^{18}$ are also of particular interest, not only because they result from an explicit assessment of need for specialist care, ${ }_{1}^{19}$ but also 
because there is evidence that referral rates are considerably higher in the United States than in other countries. ${ }^{20}$ Explicit referral is also more likely to facilitate coordination of care than when patients make visits to specialists not anticipated by the primary care physician.

To improve an understanding of what US specialists do in caring for patients, we aimed to describe the nature and content of the specialist care provided in their area of special interest. We tested 2 hypotheses. First, we hypothesized that routine follow-up appointments would constitute a large fraction of these visits, primarily induced by the specialists themselves. Second, we also hypothesized that specialists would report increased coordination of care for referred patients and would be less likely to perceive the need for a subsequent reappointment.

\section{METHODS}

Visit data from physician's offices were obtained from the National Ambulatory Medical Care Survey (NAMCS) 2002, 2003, and 2004. The survey included visits made to non-federally employed, office-based physicians in the United States. Hospital outpatient departments were excluded. Specially trained interviewers visited the physicians before their participation in the survey to instruct them on how to complete the forms and provide them with survey and reference materials. Selected physicians completed questionnaires for a systematic random sample of all patient visits made during 1 week. Additional details of the survey's methods are available elsewhere. ${ }^{21-23}$

\section{Physician Specialty}

The principal specialty of a physician was self-designated by the physicians at the time of the survey. ${ }^{21}$ We excluded all family physicians and general practitioners, general internists, and general pediatricians. ${ }^{24,25}$ Physician specialty was then classified into 4 mutually exclusive categories: medical specialists, surgical specialists, obstetrician-gynecologists, and psychiatrists. These groups have distinct clinical roles. ${ }^{24,26,27}$

\section{Type of Visit}

We developed a taxonomy of types of visits based on 2 major visit attributes as reported by the specialist: visit orientation (3 categories: primary care, referred specialty care, and nonreferred specialty care), and previous knowledge of the health problem (5 categories: new patient; known patient, new problem, known patient, known problem (recurrence), known patient, known problem (routine), and other (Table 1). ${ }^{23}$ The 5 types of visit associated with a primary care orientation-which accounted for less than $10 \%$ of visits - were excluded from the analyses, leaving 10 different types of visits in which the physicians played a self-described specialty role.

\section{Shared Care and Reappointments}

Because specialized health care is expected to be coordinated with that provided by the patient's primary care physician, ${ }^{10,11}$ we measured shared care reported by the specialist as a proxy for coordination. We instructed physicians to report that they shared a patient's care if they were providing care for a portion of the total treatment for that patient's condition and other physician(s) were also providing care. ${ }^{23}$ Reappointments occurred when a subsequent follow-up appointment had been suggested to the patient at the end of the visit.

\section{Case Mix}

We used The Johns Hopkins Adjusted Clinical Groups (ACG) Case-Mix System (http://www.acg.jhsph.edu) for measurement of morbidity burden. ${ }^{28}$ Using up to 3 different diagnoses provided by the physician for each visit, ${ }^{23}$ the system determined whether overall morbidity was related to expected very high resource use (major aggregated diagnosis group). ${ }^{28}$

\begin{tabular}{|c|c|c|c|}
\hline \multirow{2}{*}{$\begin{array}{l}\text { New } \\
\text { Patient } \\
\text { (A) }\end{array}$} & \multirow[b]{2}{*}{$\begin{array}{l}\text { Major Reason } \\
\text { for This Visit (B) }\end{array}$} & \multicolumn{2}{|c|}{ Episode of Care (C) } \\
\hline & & $\begin{array}{l}\text { Initial Visit } \\
\text { for Problem }\end{array}$ & Any Other Response \\
\hline \multirow[t]{6}{*}{ Yes } & Acute problem & New patient & New patient \\
\hline & Pre- or post-surgery & New patient & New patient \\
\hline & Chronic problem, flare-up & New patient & New patient \\
\hline & Chronic problem, routine & New patient & New patient \\
\hline & Preventive care & New patient & New patient \\
\hline & Missing & Other & Other \\
\hline \multirow[t]{6}{*}{ No } & Acute problem & $\begin{array}{l}\text { Known patient, } \\
\text { new problem }\end{array}$ & Known patient, new problem \\
\hline & Pre- or post-surgery & $\begin{array}{l}\text { Known patient, } \\
\text { new problem }\end{array}$ & Known patient, new problem \\
\hline & Chronic problem, flare-up & $\begin{array}{l}\text { Known patient, } \\
\text { new problem }\end{array}$ & $\begin{array}{l}\text { Known patient, known problem } \\
\text { (recurrence) }\end{array}$ \\
\hline & Chronic problem, routine & $\begin{array}{l}\text { Known patient, } \\
\text { new problem }\end{array}$ & $\begin{array}{l}\text { Known patient, known problem } \\
\text { (routine or preventive) }\end{array}$ \\
\hline & Preventive care & $\begin{array}{l}\text { Known patient, } \\
\text { new problem }\end{array}$ & $\begin{array}{l}\text { Known patient, known problem } \\
\text { (routine or preventive) }\end{array}$ \\
\hline & Missing & Other & Other \\
\hline
\end{tabular}

Note: For example, a visit by a known patient (A) seeking care for an acute problem (B) for the first time (C) would be categorized as known patient, new problem. These categories were applied to both primary care and non-primary care visits, but the focus of the subsequent analyses is restricted to non-primary care visits only. 


\section{Data Analysis}

The unit of analysis was the visit throughout. We obtained from the National Center for Health Statistics sampling weights that accounted for the multistage sampling design and used them to obtain national estimates of the overall numbers of visits and descriptives for all the variables. ${ }^{21,22}$ Likelihood ratios accounting for the multistage sampling design were used in testing all statistical associations between categorical variables. ${ }^{29}$ In the bivariate comparison of types of specialists, physician specialty was the independent variable, and patient and visit variables (including type of visit) were the dependent variables. We tested associations between physician specialty and continuous dependent variables by means of the overlap of confidence intervals for the estimates of each specialty group. We constructed 2 multivariate logistic regression models for the comparison between referrals and nonreferrals among visits to specialists, adjusting for patient's age, sex, ethnicity, insurance, morbidity burden, and physician specialty. ${ }^{30}$ In these analyses, the occurrence of a referral was the independent variable, and shared care and reappointment were the dependent variables.

We performed all the analysis described above for each year separately. Once the stability of the observations across the whole period had been confirmed, we pooled together all data to increase the statistical power. Only the pooled analysis is presented. The statistical software used included SPSS, version 14.0 (SPSS Inc, Chicago, Illinois), with instructions for use of the Complex Samples module as recommended by the National Center for Health Statistics, ${ }^{31}$ and the Johns Hopkins ACG Case-Mix System, version 8.0

Table 2. Descriptives of Selected Variables for All Visits

\begin{tabular}{|c|c|c|c|c|c|}
\hline Variable & $\begin{array}{c}\text { Medical } \\
\text { Specialists }\end{array}$ & $\begin{array}{c}\text { Surgical } \\
\text { Specialists }\end{array}$ & $\begin{array}{l}\text { Obstetrician- } \\
\text { gynecologists }\end{array}$ & Psychiatrists & Total \\
\hline All visits, No. (\%) & $466,116,941(36.5)$ & $515,694,813(40.3)$ & $215,791,181$ (16.9) & $80,962,250(6.3)$ & $1,278,565,185$ (100.0) \\
\hline \multicolumn{6}{|l|}{ Sex, No. (\%) } \\
\hline Female & $260,235,334(55.8)$ & $280,335,293(54.4)$ & $215,106,923(99.7)$ & $43,692,472(54.0)$ & $799,370,022(62.5)$ \\
\hline Male & $205,881,607(44.2)$ & $235,359,520(45.6)$ & $684,258(0.3)$ & $37,269,778(46.0)$ & $479,195,163(37.5)$ \\
\hline Age, mean $(95 \% \mathrm{Cl})$, y & $53.5(51.7-55.2)$ & $53.3(52.3-54.3)$ & $35.8(35.6-37.0)$ & $39.2(37.2-41.3)$ & $49.51(48.6-50.4)$ \\
\hline \multicolumn{6}{|l|}{ Ethnicity, No. (\%) } \\
\hline White, non-Hispanic & $383,527,745(82.3)$ & $420,962,462(81.6)$ & $152,905,921(70.9)$ & $69,279,960(85.6)$ & $1,026,676,088(80.3)$ \\
\hline Black, non-Hispanic & $34,902,735(7.5)$ & $41,007,894(8.0)$ & $29,297,265(13.6)$ & $5,632,784(7.0)$ & $110,840,678(8.7)$ \\
\hline Hispanic & $30,995,603(6.6)$ & $39,971,646(7.8)$ & $26,444,488(12.3)$ & $4,406,438(5.4)$ & $101,818,175(8.0)$ \\
\hline Asian/Pacific Islander & $16,690,858(3.6)$ & $13,752,811(2.7)$ & $7,143,507$ (3.3) & $1,643,068(2.0)$ & $39,230,244(3.1)$ \\
\hline \multicolumn{6}{|l|}{ Insurance, No. (\%) } \\
\hline Private insurance & $260,900,082(57.73)$ & $287,431,802$ (57.59) & $162,188,063$ (77.03) & $41,598,513(52.89)$ & $752,118,460(60.65)$ \\
\hline Medicare & $153,379,107$ (33.94) & $156,063,868(31.27)$ & $8,701,472(4.13)$ & $9,169,539$ (11.66) & $327,313,986$ (26.39) \\
\hline Medicaid/SCHIP & $23,882,076(5.28)$ & $27,827,889(5.58)$ & $31,535,961$ (14.98) & $11,034,035(14.03)$ & $94,279,961(7.60)$ \\
\hline No insurance & $13,765,906(3.05)$ & $27,743,946(5.56)$ & $8,113,992$ (3.85) & $16,854,687(21.43)$ & $66,478,531(5.36)$ \\
\hline \multicolumn{6}{|l|}{ Past visits, No. (\%) } \\
\hline 0 & $30,507,057$ (8.08) & $45,157,061$ (11.17) & $25,658,382(13.30)$ & $644,906(0.87)$ & $101,967,406(9.72)$ \\
\hline $1-2$ & $137,679,845(36.46)$ & $166,055,503$ (41.08) & $65,934,794(34.18)$ & $11,729,626(15.74)$ & $381,399,768(36.35)$ \\
\hline $3-5$ & $109,252,095(28.93)$ & $120,902,884(29.91)$ & $41,004,888(21.25)$ & $18,993,777(25.49)$ & $290,153,644(27.65)$ \\
\hline 6 or more & $100,168,775(26.53)$ & $72,066,951(17.83)$ & $60,333,886(31.27)$ & $43,142,388(57.90)$ & $275,712,000(26.28)$ \\
\hline $\begin{array}{l}\text { Time spent with } \\
\text { physician, mean } \\
(95 \% \mathrm{Cl}) \text {, min }\end{array}$ & $19.4(18.3-20.4)$ & $17.5(16.8-18.3)$ & $17.3(16.4-18.2)$ & $33.1(31.1-35.1)$ & $19.2(18.6-19.7)$ \\
\hline \multicolumn{6}{|l|}{$\begin{array}{c}\text { Major ADG as primary } \\
\text { diagnosis, No. (\%) }\end{array}$} \\
\hline Yes & $129,973,814(27.9)$ & $86,812,987$ (16.8) & $2,189,475(1.0)$ & $37,648,031(46.5)$ & $256,624,307$ (20.1) \\
\hline No & $336,143,127(72.1)$ & $428,881,826(83.2)$ & $213,601,706(99.0$ & $43,314,219(53.5)$ & $1,021,940,878(79.9)$ \\
\hline $\begin{array}{l}\text { Number of diagnoses, } \\
\text { mean }(95 \% \mathrm{Cl})\end{array}$ & $1.81(1.76-1.87)$ & $1.62(1.59-1.65)$ & $1.36(1.31-1.41)$ & $1.56(1.48-1.63)$ & $1.64(1.61-1.67)$ \\
\hline \multicolumn{6}{|l|}{$\begin{array}{l}\text { Visit orientation, } \\
\text { No. (\%) }\end{array}$} \\
\hline Primary care & $49,384,112(10.6)$ & $19,706,986(3.8)$ & $40,442,490(18.7)$ & $2,979,065(3.7)$ & $112,512,653(8.8)$ \\
\hline Specialty care & $416,732,829(89.4)$ & $495,987,827$ (96.2) & $175,348,691(82.3)$ & $77,983,185(96.3)$ & $1,166,052,532$ (91.2) \\
\hline
\end{tabular}


(Johns Hopkins Bloomberg School of Public Health, Baltimore, Maryland).

\section{RESULTS}

\section{Description of Specialists Visits}

Data were available for $1,278,565,185$ visits to specialists $(52,125$ nonweighted visits). Overall, $46.3 \%$ of visits had 2 or more diagnoses. In 1 in 4 visits, the physician reported having seen the patient at least 6 times in the previous 12 months.

Significant differences were observed by physician specialty group in age, sex, and insurance status of patients (Table 2). There were also differences in morbidity burden, mean number of diagnoses, and visit duration across the defined physician specialty groups.
Routine Follow-up in Visits to Specialists

Routine or preventive visits by known patients emerged as the most frequent type of visit, accounting for 540,278,250 visits overall (46.3\%), for the great majority of all visits to obstetrician-gynecologists $(64.3 \%)$ and psychiatrists $(73.7 \%)$, and for slightly more than one-half of all visits to medical specialists $(52.4 \%)$ (Table 3$)$. Only $1.9 \%$ of visits were in the category of other.

\section{Referred and Nonreferred Care}

The 354,175,323 visits for patients referred from other physicians constituted $30.4 \%$ of all specialty care visits (Table 3). Although there were no differences in age or ethnicity between referred and nonreferred visits, referred visits included a higher proportion of patients

Table 3. Types of Visits and Frequency of Reappointments by Physician Specialty (Specialty Care Visits Only)

\begin{tabular}{|c|c|c|c|c|c|}
\hline $\begin{array}{l}\text { Visit } \\
\text { Characteristics }\end{array}$ & $\begin{array}{l}\text { Medical } \\
\text { Specialists } \\
\text { No. ( } \%)\end{array}$ & $\begin{array}{c}\text { Surgical } \\
\text { Specialists } \\
\text { No. (\%) }\end{array}$ & $\begin{array}{c}\text { Obstetrician- } \\
\text { Gynecologists } \\
\text { No. (\%) }\end{array}$ & $\begin{array}{c}\text { Psychiatrists } \\
\text { No. ( } \%)\end{array}$ & $\begin{array}{l}\text { All Visits } \\
\text { No. }(\%)\end{array}$ \\
\hline \multicolumn{6}{|l|}{ Type of visit } \\
\hline \multicolumn{6}{|l|}{ New patient } \\
\hline Referred & $50,432,210(38.2)$ & $70,200,541(38.5)$ & $7,759,568(33.6)$ & $3,193,437$ (18.9) & $13,1585,756(37.2)$ \\
\hline Not referred & $30,923,570(10.9)$ & $32,540,316(10.4)$ & $11,682,421(7.7)$ & $2,644,147(4.3)$ & $77,790,454(9.6)$ \\
\hline Overall & $81,355,780(19.5)$ & $102,740,857(20.7)$ & $19,441,989(11.1)$ & $5,837,584(7.5)$ & $209,376,210(18.0)$ \\
\hline \multicolumn{6}{|c|}{ Known patient, new problem } \\
\hline Referred & $20,949,555(15.9)$ & $62,697,838(34.4)$ & $4,183,533(18.1)$ & $1,615,124(9.6)$ & $8,944,6050(25.3)$ \\
\hline Not referred & $55,484,409(19.5)$ & $135,564,474(43.3)$ & $31,519,810(20.7)$ & $1,791,859(2.9)$ & $224,360,552(27.6)$ \\
\hline Overall & $76,433,964(18.3)$ & $198,262,312(40.0)$ & $35,703,343(20.4)$ & $3,406,983(4.4)$ & $313,806,602(26.9)$ \\
\hline \multicolumn{6}{|c|}{ Known patient, known problem: recurrence } \\
\hline Referred & $9,040,755(6.9)$ & $9,989,434(5.5)$ & $506,161(2.2)$ & $1,739,320(10.3)$ & $2,1275,670(6.0)$ \\
\hline Not referred & $23,842,104(8.4)$ & $23,568,943(7.5)$ & $3,543,953(2.3)$ & $7,786,750(12.7)$ & $5,8741,750(7.2)$ \\
\hline Overall & $32,882,859(7.9)$ & $33,558,377(6.8)$ & $4,050,114(2.3)$ & $9,526,070(12.2)$ & $8,0017,420(6.9)$ \\
\hline \multicolumn{6}{|c|}{ Known patient, known problem, routine or preventive } \\
\hline Referred & $50,241,347(38.1)$ & $36,542,497(20.0)$ & $9,585,362(41.5)$ & $10,167,954(60.2)$ & $10,6537,160(30.1)$ \\
\hline Not referred & $168,094,186(59.0)$ & $115,099,839(36.7)$ & $103,209,997(67.8)$ & $47,337,068(77.5)$ & $433,741,090(53.4)$ \\
\hline Overall & $218,335,533(52.4)$ & $151,642,336(30.6)$ & $112,795,359(64.3)$ & $57,505,022(73.7)$ & $540,278,250(46.3)$ \\
\hline \multicolumn{6}{|l|}{ Other } \\
\hline Referred & $1,266,203(1.0)$ & $2,836,052(1.6)$ & $1,058,081$ (4.6) & $170,351(1.0)$ & $5,330,687(1.5)$ \\
\hline Not referred & $6,458,490(2.3)$ & $6,947,893(2.2)$ & $2,299,805(1.5)$ & $1,537,175(2.5)$ & $17,243,363(2.1)$ \\
\hline Overall & $7,724,693$ (1.9) & $9,783,945(2.0)$ & $3,357,886(1.9)$ & $1,707,526(2.2)$ & $22,574,050(1.9)$ \\
\hline \multicolumn{6}{|l|}{ Shared care } \\
\hline Referred & $72,734,619(56.0)$ & $83,164,843(46.4)$ & $7,942,808(37.4)$ & $3,697,267(22.3)$ & $167,711,222(48.0)$ \\
\hline Not referred & $78,080,308(28.1)$ & $65,704,184(21.4)$ & $33,472,995(22.5)$ & $8,289,358(14.0)$ & $186,378,057(23.2)$ \\
\hline Overall & $150,814,927$ (37.0) & $148,869,027$ (30.7) & $41,415,803(24.3)$ & $11,986,625(15.8)$ & $354,089,279(30.7)$ \\
\hline \multicolumn{6}{|l|}{ Reappointments } \\
\hline Referred & $96,390,830(73.1)$ & $124,589,758(68.4)$ & $13,434,294(58.2)$ & $15,426,153$ (91.4) & $250,997,151$ (70.6) \\
\hline Not referred & 217,382,015 (76.3) & $226,893,374(72.3)$ & $107,602,751$ (70.7) & $56,909,990(93.1)$ & $617,375,536(75.1)$ \\
\hline Overall & $313,772,845(75.3)$ & $351,483,132$ (70.9) & $121,037,045$ (69.0) & $72,336,143(92.8)$ & $858,629,165(73.6)$ \\
\hline \multicolumn{6}{|l|}{ Overall } \\
\hline Referred & $131,930,070$ (100) & $182,266,362(100)$ & $23,092,705(100)$ & $16,886,186(100)$ & $354,175,323(100)$ \\
\hline Not referred & $284,802,759(100)$ & $313,721,465(100)$ & $152,255,986(100)$ & $61,096,999(100)$ & $811,877,209(100)$ \\
\hline Overall & $416,732,829$ (100) & 495,987,827 (100) & $175,348,691$ (100) & $77,983,185(100)$ & $1,166,052,532(100)$ \\
\hline
\end{tabular}




\begin{tabular}{|c|c|c|}
\hline Variables, Categories & Odds Ratio & $95 \% \mathrm{Cl}$ \\
\hline \multicolumn{3}{|l|}{ Specialty } \\
\hline Medical specialists & Reference & Reference \\
\hline Surgical specialists & 0.73 & $0.60-0.89$ \\
\hline Obstetrician-gynecologists & 0.78 & $0.51-1.19$ \\
\hline Psychiatrists & 0.38 & $0.26-0.56$ \\
\hline \multicolumn{3}{|l|}{ Referral status } \\
\hline Not referred & Reference & Reference \\
\hline Referred & 2.99 & $2.52-3.55$ \\
\hline \multicolumn{3}{|l|}{ Morbidity burden } \\
\hline No major ADG & Reference & Reference \\
\hline Major ADG & 1.39 & $1.21-1.61$ \\
\hline \multicolumn{3}{|l|}{ Sex } \\
\hline Female & Reference & Reference \\
\hline Male & 0.96 & $0.89-1.04$ \\
\hline \multicolumn{3}{|l|}{ Ethnicity } \\
\hline White, non-Hispanic & Reference & Reference \\
\hline Black, non-Hispanic & 1.00 & $0.85-1.19$ \\
\hline Hispanic & 1.35 & $1.08-1.68$ \\
\hline Asian/Pacific Islander & 1.63 & $1.08-2.45$ \\
\hline \multicolumn{3}{|l|}{ Insurance } \\
\hline Private insurance & Reference & Reference \\
\hline Medicare & 0.95 & $0.83-1.08$ \\
\hline Medicaid & 1.05 & $0.85-1.30$ \\
\hline No insurance & 0.55 & $0.44-0.68$ \\
\hline \multicolumn{3}{|l|}{ Age } \\
\hline $0-17$ y & Reference & Reference \\
\hline $18-64$ y & 1.19 & $1.001-1.41$ \\
\hline$\geq 65 y$ & 1.39 & $1.14-1.69$ \\
\hline \multicolumn{3}{|l|}{$\mathrm{ADG}=$ aggregated diagnosis group.} \\
\hline Note: Response category is "No." & & \\
\hline
\end{tabular}

with private insurance $(64.0 \%$ vs $59.3 \%, P<.05)$. Male patients were also overrepresented $(42.6 \%$ vs $36.3 \%$, $P<.05)$, mainly because $86.8 \%$ of obstetrician-gynecologists visits were not referred. Compared with nonreferred visits, referred visits lasted about $20 \%$ longer ( 21.6 minutes vs 18.2 minutes, $P<.05)$ and included slightly more patients with higher overall morbidity burdens $(22.6 \%$ vs $20.0 \%, P<.05)$.

Most referred care visits $(62.5 \%)$ involved care for either a new patient $(37.2 \%)$ or a new problem in a known patient $(25.3 \%)$, whereas nonreferred care was mainly for routine or preventive care (53.4\%). Routine or preventive care for nonreferred patients was the most common type of visit, outnumbering all other categories of referred visits combined.

\section{Shared Care and Reappointments}

Specialists reported sharing care for the patient with another physician in only $30.7 \%$ of all visits. Shared care was more likely to be reported for referred
Table 5. Likelihood of Reappointment: Multiple Logistic Regression Analysis

\begin{tabular}{|c|c|c|}
\hline Variables, Categories & Odds Ratio & $95 \% \mathrm{Cl}$ \\
\hline \multicolumn{3}{|l|}{ Specialty } \\
\hline Medical specialists & Reference & Reference \\
\hline Surgical specialists & 0.85 & $0.71-1.02$ \\
\hline Obstetrician-gynecologists & 0.87 & $0.63-1.19$ \\
\hline Psychiatrists & 4.36 & $3.18-5.97$ \\
\hline \multicolumn{3}{|l|}{ Referral status } \\
\hline Not referred & Reference & Reference \\
\hline Referred & 0.80 & $0.70-0.91$ \\
\hline \multicolumn{3}{|l|}{ Morbidity burden } \\
\hline No major ADG & Reference & Reference \\
\hline Major ADG & 1.54 & $1.35-1.76$ \\
\hline \multicolumn{3}{|l|}{ Sex } \\
\hline Female & Reference & Reference \\
\hline Male & 1.07 & $0.999-1.14$ \\
\hline \multicolumn{3}{|l|}{ Ethnicity } \\
\hline White, non-Hispanic & Reference & Reference \\
\hline Black, non-Hispanic & 1.03 & $0.85-1.26$ \\
\hline Hispanic & 1.02 & $0.87-1.19$ \\
\hline Asian/Pacific Islander & 1.15 & $0.88-1.51$ \\
\hline \multicolumn{3}{|l|}{ Insurance } \\
\hline Private insurance & Reference & Reference \\
\hline Medicare & 1.32 & $1.18-1.48$ \\
\hline Medicaid & 1.41 & $1.16-1.70$ \\
\hline No insurance & 0.74 & $0.62-0.89$ \\
\hline \multicolumn{3}{|l|}{ Age } \\
\hline $0-17$ years & Reference & Reference \\
\hline 18-64 years & 1.07 & $0.90-1.26$ \\
\hline$\geq 65$ years & 1.23 & $0.997-1.53$ \\
\hline \multicolumn{3}{|l|}{ ADG = aggregated diagnosis group } \\
\hline Note: Response category is "No." & & \\
\hline
\end{tabular}

patients than for nonreferred patients $(48.0 \%$ vs $23.2 \%$, $P<.05$; adjusted odds ratio $[\mathrm{OR}]=2.99 ; 95 \%$ confidence interval $[\mathrm{CI}], 2.52-3.55$ ) (Table 4).

A reappointment was scheduled in about 3 of 4 visits. Overall, almost 3 of 5 reappointments resulted from a routine or preventive care visit (58.3\%). The likelihood of a reappointment in referred visits was smaller than in visits for nonreferred patients $(70.6 \%$ vs $75.1 \%, P<0.05$; adjusted $\mathrm{OR}=0.80 ; 95 \% \mathrm{CI}, 0.70-0.91)$ (Table 5).

\section{DISCUSSION}

This profile of the more than 1 billion ambulatory visits to office-based specialists in 2002 through 2004 showed a considerable variation across physician specialties in the patient and visit profiles, but clear patterns emerged. Routine and preventive care for patients already known to the physician accounted for one-half of visits, and most of these visits resulted in a subsequent appointment with the same physician. Referrals by other profes- 
sionals accounted for less than one-third of all specialty care visits, with patients having been referred for a variety of different visit types. For patients without a referral, specialists had one-third the odds of sharing the patient's care with another physician.

\section{Routine Care in the Practices of Specialists}

We have shown that routine and preventive visits are the cornerstone of the activity among specialists in office-based practice, as well as the source of future such visits through follow-up appointments. This finding was especially true for nonreferred care.

There is little evidence to suggest how frequently patients with common chronic conditions need specialist follow-up, and there is considerable variation in the frequencies and intervals at which specialists request that their patients make return visits. At least for elective surgery, controlled trials suggest that this practice might be unnecessary and not cost-effective. ${ }^{32}$ In countries such as the United Kingdom, which has well-developed systems of primary care, the routine follow-up of patients with common chronic conditions is undertaken in primary care.

\section{Referrals and Shared Care}

We did not consider any type of visit to be inappropriate for specialized care. What constitutes appropriate seeking of care from specialists is unknown and undoubtedly varies by place and time. In the United States the rate of referral from primary care physicians is twice that in the United Kingdom. ${ }^{20}$ The reasons for higher specialist use in the United States ${ }^{33}$ are likely to be many, including common self-referral of patients in the United States, fee-for-service payment in the United States as opposed to the salaried arrangements for consultants in many countries, the greater supply of specialists per capita, and the less-comprehensive nature of primary care in the United States. ${ }^{25,34}$ Absence of a usual source of care for many patients may account for both self-referral ${ }^{35,36}$ and for some of the specialists' failure to share care with other physicians.

Primary care practices in the United States are less comprehensive than those of other countries, thus requiring much more to be undertaken by specialists, which at least in part may also account for the much higher costs of care in the United States. ${ }^{37}$ In the face of increasing comorbidity in populations and with recognition of a greater need for coordination of care, the potential for explicitly shared care may become an important issue for exploration.

\section{Limitations of the Study}

There are several limitations to this study. First, the medical and surgical specialty groups used in this study each included more than 20 different specialties, ${ }^{21}$ so it is unclear whether our findings are applicable to all subspecialties or only to some. Further research is needed to refine this analysis.

Second, the distinction between referred and nonreferred patients could in part be an artifact of followup. Given the infrequency with which primary care physicians send letters to specialists, ${ }^{38}$ it is possible that specialists underestimate which patients were referred. For patients already known to the physician, specialists might not have considered the visit to be a referral even if it was. Furthermore, although the survey instrument clearly specified that referral had to have occurred in relation to that particular visit, it is possible that this instruction was misunderstood by some physicians. ${ }^{23}$

Third, measurements were largely based on physician reports of the content of individual visits. Evidence suggests that self-report of visit duration is particularly susceptible to overestimation. ${ }^{39}$ Observations based on this variable should therefore be interpreted with caution.

Fourth, the NAMCS survey includes data on ambulatory encounters only. Our findings do not apply to any other type of care provided by office-based specialists, notably care provided to hospitalized patients or same-day procedures performed in surgical centers. In addition, our analyses are limited to visits in which the specialists reported not being in a primary care role, which excludes 1 in 10 visits.

Finally, more recent analyses of NAMCS data (2005) were not included because relevant variables had been removed from the survey, notably "episode of care" and "shared care" (Table 1). This change in NAMCS has implications for the ability of subsequent research that further explores the nature of specialist care in the United States.

\section{Implications for Research and Policy}

Several decades ago, the observation that about 1 in 5 Americans received primary care provided by a specialist led to the notion of a hidden system of primary care. Perceived shortages of generalists were therefore not as great as they seemed if one counted only primary care doctors. ${ }^{40}$ This notion was subsequently dispelled by observations that specialists reporting a primary care function were not functioning as primary care physicians: they rarely were the patient's principal care physician, they provided little care outside their usual clinical domain, and they did not take responsibility for routine immunizations. ${ }^{41}$

The results of our study suggest now that not all activity performed by specialists when in a specialist role may require specialized care. In most organized health systems, common health problems are dealt with 
in primary care ${ }^{37}$ but the US health system has, in the past century, become increasingly specialty oriented, with consequent high costs and no additional health benefit. ${ }^{42}$ The Institute of Medicine has recognized that primary care professionals are accountable for the great majority of personal health care needs, ${ }^{9}$ and some routine follow-up activities now carried out by specialists could be transferred to primary care. Expanding primary care provision in the United States therefore appears a feasible alternative to increasing the supply of specialists. This alternative would be consistent with the concept of a medical home and might be feasible for a substantial proportion of the about 434 million office-based ambulatory visits to specialists related to nonreferred routine management of known patients.

The superiority of care provided by specialists has been recently called into question, ${ }^{43}$ with the suggestion that greater efficiency could be achieved by having the primary care physician do the follow-up care, allowing specialists to focus on those aspects of care that demand their unique skills. ${ }^{44}$ Although the specific clinical content of these activities remains to be determined, likely candidates are routine follow-up of chronic diseases and routine preventive services, such as cervical cancer screening. In the United Kingdom, a country with better health outcomes than the United States ${ }^{45}$ most preventive management of chronic disease is carried out in primary care, while achieving high levels of quality of care. ${ }^{46}$

Inexorable increases in costs of care in the United States appear to be sufficient justification for reassessing the appropriate relative roles of primary care and specialists physicians.

To read or post commentaries in response to this article, see it online at http://www.annfammed.org/cgi/content/full/7/2/104.

Key words: Primary health care; specialism; health services; referral and consultation

Submitted April 8, 2008; submitted, revised, July 4, 2008; accepted August 4, 2008.

\section{References}

1. Association of American Medical Colleges. Recent Studies and Reports on Physician Shortages in the US, 2006. http://www.aamc. org/workforce/rcntwrkfce.pdf. Accessed May 15, 2007.

2. Association of American Medical Colleges. AAMC Statement on the Physician Workforce. 2006. http://www.aamc.org/workforce/workforceposition.pdf. Accessed May 15, 2007.

3. Yamamoto LG. We have a shortage of specialists. Am J Emerg Med. 2005;23(7):895-896

4. Blumenthal D. New steam from an old cauldron-the physician supply debate. N Engl J Med. 2004;350(17):1780-1787.

5. Salsberg E. Physician workforce shortages: implications and issues for academic health centers and policymakers. Acad Med. 2006;81(9):782-787.
6. Goodman DC, Fisher ES. Physician workforce crisis? Wrong diagnosis, wrong prescription. N Engl J Med. 2008 17;358(16):1658-1661.

7. Goodman DC, Grumbach K. Does having more physicians lead to better health system performance? JAMA. 2008 23;299(3):335-337.

8. Starfield B, Lemke KW, Herbert R, Pavlovich WD, Anderson G. Comorbidity and the use of primary care and specialist care in the elderly. Ann Fam Med. 2005;3(3):215-222.

9. Donaldson M, Yordy K, Lohr K, et al. Primary Care: America's Health in a New Era. Washington, DC: Institute of Medicine; 1996.

10. Starfield B. Primary Care: Balancing Health Needs, Services, and Technology. Oxford University Press; 1998.

11. Starfield B, Shi L. The medical home, access to care, and insurance: a review of evidence. Pediatrics. 2004;113(5)(Suppl):1493-1498.

12. Grumbach K, Bodenheimer T. A primary care home for Americans: putting the house in order. JAMA. 2002;288(7):889-893.

13. Barr M, Ginsburg J. The Advanced Medical Home: A Patient-Centered, Physician-Guided Model of Health Care. American College of Physicians. 2006. http://www.acponline.org/advocacy/where_we_stand/ policy/adv_med.pdf.

14. Starfield B, Shi L, Macinko J. Contribution of primary care to health systems and health. Milbank Q. 2005;83(3):457-502.

15. Forrest $C B$, Glade GB, Baker AE, Bocian AB, Kang M, Starfield $B$. The pediatric primary-specialty care interface: how pediatricians refer children and adolescents to specialty care. Arch Pediatr Adolesc Med. 1999;153(7):705-714.

16. Forrest CB, Reid RJ. Prevalence of health problems and primary care physicians' specialty referral decisions. J Fam Pract. 2001;50(5): 427-432.

17. Forrest $C B$, Reid RJ. Passing the baton: HMOs' influence on referrals to specialty care. Health Aff (Millwood). 1997;16(6):157-162.

18. American Medical Association. Glossary of Methodologic Terms. 2007. http://jama.ama-assn.org/content/vol295/issue1/images/ data/103/DC4/JAMA_auinst_term.dtl. Accessed Jul 15, 2007.

19. Forrest CB, Nutting PA, Starfield B, von Schrader S. Family physicians' referral decisions: results from the ASPN referral study. J Fam Pract. 2002;51(3):215-222.

20. Forrest CB, Majeed A, Weiner JP, Carroll K, Bindman AB. Comparison of specialty referral rates in the United Kingdom and the United States: retrospective cohort analysis. BMJ. 2002;325(7360):370-371.

21. Hing E, Cherry DK, Woodwell DA. National Ambulatory Medical Care Survey: 2004 summary. Adv Data. 2006(374)1-33.

22. Hing E, Burt CW. Characteristics of office-based physicians and their practices: United States, 2003-04. Vital Health Stat 13. 2007(164)1-34.

23. Center for Disease Control. 2004 NAMCS Micro-Data File Documentation. http://www.cdc.gov/nchs/about/major/ahcd/ahcd1.htm\#Microdata. Accessed Jan 15, 2008.

24. Weiner JP, Starfield BH. Measurement of the primary care roles of office-based physicians. Am J Public Health. 1983;73(6):666-671.

25. Rosenblatt RA, Hart LG, Gamliel S, Goldstein B, McClendon BJ. Identifying primary care disciplines by analyzing the diagnostic content of ambulatory care. J Am Board Fam Pract. 1995;8(1):34-45.

26. Franks P, Clancy CM, Nutting PA. Defining primary care: empirical analysis of the National Ambulatory Medical Care Survey. Med Care. 1997;35(7):655-668.

27. Lasker RD, Marquis MS. The intensity of physicians' work in patient visits-implications for the coding of patient evaluation and management services. N Engl J Med. 1999;341(5):337-341.

28. Weiner J, Abrams C, eds. The Johns Hopkins ACG Case-Mix System. September 2006. http://acg.jhsph.edu. Accessed Apr 10, 2007.

29. Särndal C, Swensson B, Wretman J. Model Assisted Survey Sampling. New York, NY: Springer-Verlag; 1992. 
30. Kleinbaum DG, Kupper LL, Muller LL. Applied Regression Analysis and Other Multivariable Methods. Boston, MA: PWS Publishing Co; 1998.

31. National center for Health Statistics. Using Ultimate Cluster Models with NAMCS and NHAMCS Public Use Files. 2004. http://www.cdc. gov/nchs/about/major/ahcd/ahcd1.htm. Accessed Jun 24, 2008).

32. Bailey J, Roland M, Roberts C. Is follow up by specialists routinely needed after elective surgery? A controlled trial. J Epidemiol Community Health. 1999;53(2):118-124.

33. Sicras-Mainar A, Serrat-Tarrés J, Navarro-Artieda R, Llausí-Sellés R, Ruano-Ruano I, González-Ares JA. Adjusted clinical groups use as a measure of the referrals efficiency from primary care to specialized care in Spain. Eur J Public Health. 2007;17(6):657-663.

34. Bindman $A B$, Forrest $C B$, Britt $H$, Crampton $P$, Majeed $A$. Diagnosti scope of and exposure to primary care physicians in Australia, New Zealand, and the United States: cross sectional analysis of results from three national surveys. BMJ. 2007;334(7606):1261.

35. Braun BL, Fowles JB, Forrest CB, Kind EA, Foldes SS, Weiner JP. Which enrollees bypass their gatekeepers in a point-of-service plan? Med Care. 2003;41(7):836-841.

36. Forrest $C B$, Weiner JP, Fowles J, et al. Self-referral in point-of-service health plans. JAMA. 2001;285(17):2223-2231.

37. Enthoven A, Fuchs VR, Ginsburg PB, Starfield B. Reforming America's Health Care System: Messages to Major Purchasers. Washington, DC: HR Policy Association; 2006

38. Gandhi TK, Sittig DF, Franklin M, Sussman AJ, Fairchild DG, Bates DW. Communication breakdown in the outpatient referral process. J Gen Intern Med. 2000;15(9):626-631.
39. Gilchrist VJ, Stange KC, Flocke SA, McCord G, Bourguet CC. A comparison of the National Ambulatory Medical Care Survey (NAMCS) measurement approach with direct observation of outpatient visits. Med Care. 2004;42(3):276-280.

40. Aiken LH, Lewis CE, Craig J, Mendenhall RC, Blendon RJ, Rogers $\mathrm{DE}$. The contribution of specialists to the delivery of primary care. N Engl J Med. 1979;300(24):1363-1370.

41. Rosenblatt RA, Hart G, Baldwin L, Chan L, Schneeweiss R. The generalist role of specialty physicians: is there a hidden system of primary care? JAMA. 1998;279(17):1364-1370.

42. Starfield B, Shi L, Grover A, Macinko J. The effects of specialist supply on populations' health: assessing the evidence. Health Aff (Millwood). 2005;(Suppl 1):W5-97-W5-107.

43. Smetana GW, Landon BE, Bindman AB, et al. A comparison of outcomes resulting from generalist vs specialist care for a single discrete medical condition: a systematic review and methodologic critique. Arch Intern Med. 2007;167(1):10-20.

44. Starfield B. Primary and specialty care interfaces: the imperative of disease continuity. Br J Gen Pract. 2003;53(494):723-729.

45. Banks J, Marmot M, Oldfield Z, Smith J. Disease and disadvantage in the United States and in England. JAMA. 2006;295(17):2037-2045.

46. Doran T, Fullwood C, Gravelle H, et al. Pay-for-performance programs in family practices in the United Kingdom. N Engl J Med. 2006;355(4):375-384. 